\title{
Maritime Oil Spill Risk Assessment for Hanhikivi Nuclear Power Plant
}

\author{
Juho Helander \\ Fennovoima Oy, Nuclear Safety Department, Nuclear and Radiation Safety Unit, Helsinki 00180, Finland
}

Received: September 18, 2014 / Accepted: November 05, 2014 / Published: February 28, 2015.

\begin{abstract}
Fennovoima is planning to build a new nuclear power plant unit-Hanhikivi 1, on a greenfield site in Northern Finland. A nearby maritime oil spill accident is one of the external events analysed in the probabilistic risk assessment of the plant. In the worst case, the oil could cause a loss of the ultimate heat sink by blocking the sea water intake screens. By considering the maritime traffic, oil transport and oil spill accident data in the Baltic Sea area, the annual probabilities of nearby, significant oil spills are evaluated. Event tree analysis is used to evaluate the probability that significant amount of oil enters the plant intake tunnel. The spill behaviour is considered, including oil spreading, dissolution, dispersion and movement due to wind and currents. In addition, oil combat measures including the use of oil booms and skimmers are evaluated.
\end{abstract}

Key words: Probabilistic risk assessment, oil spill, oil accident, event tree analysis, Baltic Sea.

\section{Introduction}

An accidental oil spill at the sea near a nuclear power plant could affect the safe operation of the plant. The oil could enter the sea water intake, block the fine screens and basket chain filters and lead to loss of sea water cooling. This report presents an evaluation of the oil risk regarding the Hanhikivi nuclear power plant, which will be constructed in northern Finland in Pyhäjoki at the coast of the Bothnian Bay. Dozens of small oil spills are observed annually in the Finnish sea areas of the Baltic Sea. However, only large scale accidents related to oil tankers or other large ships containing large amounts of fuel oil could have an impact on the operation of a nuclear power plant.

In this report, a method for oil risk evaluation is presented. The accident frequencies are evaluated by using the accident data and maritime traffic volumes in the Baltic Sea and specifically in the Bothnian Bay. The accident propagation is modelled and quantified by using event tree analysis. The drifting direction of

Corresponding author: Juho Helander, reliability manager, research fields: statistics, reliability analysis, nuclear engineering. E-mail: juho.helander@fennovoima.fi. the oil spill, the reporting of the accident and oil combat measures at the open sea and near Hanhikivi are considered in the event trees. Also sensitivity and uncertainty analyses are performed.

\section{Evaluation Method}

Let us give the following definition for the oil initiating event: "significant amount of oil enters the sea water intake tunnel of the plant". The evaluation of the oil initiating event frequency includes the following evaluation phases:

(1) Frequency of a nearby maritime oil spill accident;

(2) Impact probability (the oil spill travels to Hanhikivi);

(3) Probability that oil combat measures fail.

According to expert judgement, the operation of a nuclear power plant could be affected if $1 \mathrm{t}$ of oil enters the intake tunnel, although no detailed studies have been performed. Furthermore, it can be assumed that at most $1 \%$ of the spill total volume enters the intake tunnel. According to these assumptions, all oil spills that reach Hanhikivi and contain at least $100 \mathrm{t}$ of oil 
should be considered. Accident frequencies are calculated by using the compromise version of the PREB (parametric robust empirical bayes) evaluation method described in Ref. [1].

The spill impact probability is assessed by considering oil product properties and prevailing wind and current conditions. The spill propagation can be prevented by using oil combat measures at the open sea and near Hanhikivi. Event tree analysis is used to determine the annual probability that significant amount of oil enters the plant intake tunnel.

The oil spill risks for the existing Finnish nuclear power plants (Loviisa and Olkiluoto) have been evaluated by using similar methods described in Refs. $[2,3]$.

\section{Oil Accident Probability}

\subsection{Location of the Hanhikivi Site}

The Baltic Sea is a Mediterranean Sea in northern Europe bounded by Finland, Sweden, Denmark, Germany, Poland, Lithuania, Latvia, Estonia and Russia. Fennovoima's nuclear power plant site is located at the coast of Bothnian Bay, which is the northernmost part of the Baltic Sea. The Bothnian Bay is relatively shallow with an average depth of approximately $40 \mathrm{~m}$ and a maximum depth of $147 \mathrm{~m}$. The surface area of Bothnian Bay is roughly 37,000 $\mathrm{km}^{2}$, the salinity ranges between $0.2 \%$ and $0.4 \%$ and the sea is covered by an ice sheet typically from December to May.

\subsection{Maritime Traffic in the Baltic Sea and the Bothnian Bay}

The ship traffic volumes in the Bothnian Bay are relatively low when compared to other parts of the Baltic Sea. Fig.1 illustrates the location of the Baltic Sea and its subregions (Fig. 1a), the ship movements in the Baltic Sea area during one week in 2008 (Fig. 1b) and all the significant ports at the Bothnian Bay coast (Fig. 1c). The Hanhikivi site is located between Kalajoki and Raahe.
Most of the sea transports in the Bothnian Bay are related to other than oil products. No crude oil is being transported in the whole Gulf of Bothnia. The oil products transported include: coal tar, benzene, propane, butane, liquefied natural gas, gasoline, kerosene and diesel fuel. Only relatively small ships can operate in the Bothnian Bay because the quays in the ports are typically less than $10 \mathrm{~m}$ deep. A typical cargo ship or oil tanker operating in the Bothnian Bay has a DWT (deadweight tonnage; a measure of how much weight a ship can carry, including cargo, fuel, fresh water, ballast water, provisions, passengers and crew) of roughly $10,000 \mathrm{t}$ and draught between $6 \mathrm{~m}$ and $8 \mathrm{~m}$. This also limits the size of the maximum possible oil spill [4].

Statistics of the Bothnian Bay ports are presented in Table 1. The table presents the sum of all cargo handled in the port annually. In addition, the sum of all liquid bulk cargo (including oil products, liquid chemicals and other liquid bulk) handled in the port is presented to give an insight on how much oil products are transported. Also the annual number of all ships and tankers visiting the port are presented. The target is to estimate which share of the Baltic Sea maritime traffic takes place in the Bothnian Bay, and by using this information, to deduce which share of the Baltic Sea oil spill accidents occurs in the Bothnian Bay. The Bothnian Bay accident data alone is insufficient for reliable estimation.

The figures indicate that roughly $4 \%$ of all cargo handled in the Baltic Sea area is handled in the Bothnian Bay ports. However, the share in liquid bulk products is only $1.1 \%$, which is consistent with the fact that the Baltic Sea oil transportation is concentrated in the Gulf of Finland. In terms of ship visits, the share of Bothnian Bay is $1.3 \%$. It can be concluded that $1 \%$ to $4 \%$ of all maritime traffic in the Baltic Sea occurs in the Bothnian Bay, depending on the factor considered. In this report, we assume that the share is $2 \%$, which is the average from the three different share estimates. Thus, we assume that $2 \%$ of the oil spill accidents in the Baltic Sea occur in the Bothnian Bay. 


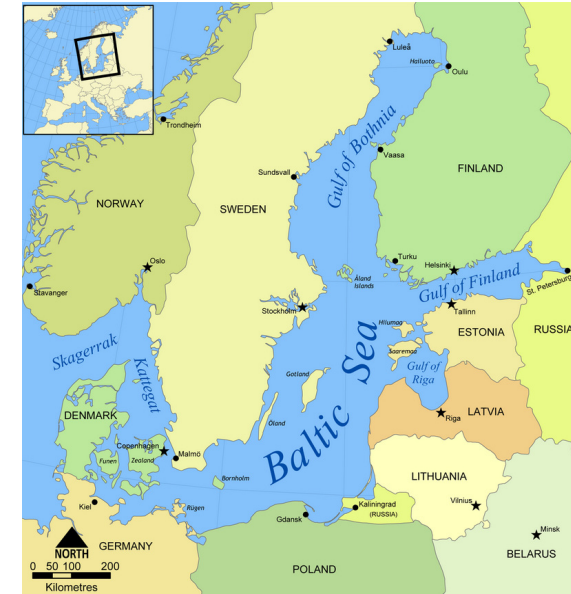

(a)

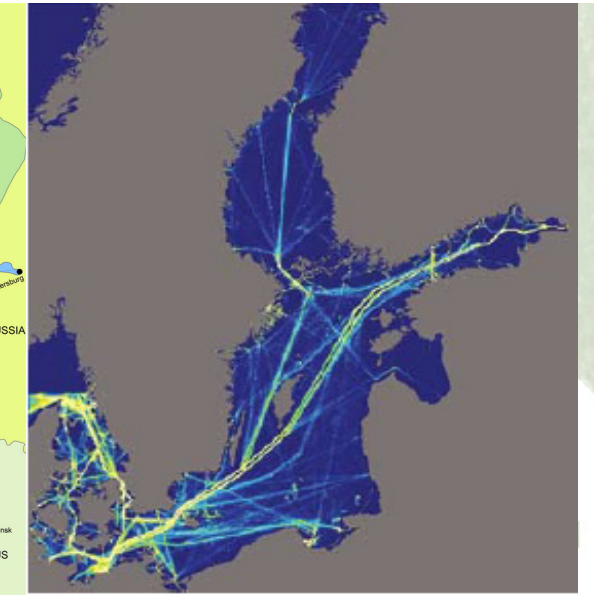

(b)

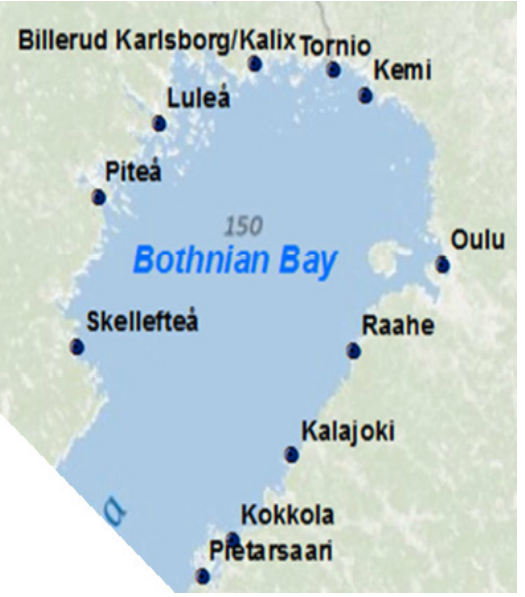

(c)

Fig. 1 (a) Baltic Sea location and subregions; (b) ship movements in the Baltic Sea during one week in 2008; (c) main ports in the Bothnian Bay coast [5].

Table 1 Bothnian Bay port statistics in 2006 [6-9].

\begin{tabular}{|c|c|c|c|c|c|}
\hline Port name & Country & Cargo (million tonnes) & Liquid bulk (million tonnes) & Ships & Tankers \\
\hline Pietarsaari & Finland & 1.54 & 0.16 & 393 & 25 \\
\hline Kokkola & Finland & 5.32 & 0.86 & 600 & 161 \\
\hline Kalajoki Rahja & Finland & 0.29 & 0.00 & 74 & 0 \\
\hline Raahe & Finland & 6.09 & 0.05 & 703 & 66 \\
\hline Oulu & Finland & 2.99 & 0.97 & 586 & 144 \\
\hline Kemi & Finland & 2.71 & 0.13 & 740 & 67 \\
\hline Tornio & Finland & 1.89 & 0.09 & 425 & $10^{*}$ \\
\hline Kalix & Sweden & 0.17 & 0.00 & 36 & 0 \\
\hline Billerud Karlsborg & Sweden & 0.10 & 0.02 & 33 & $2^{*}$ \\
\hline Luleå & Sweden & 7.49 & 0.35 & 603 & 31 \\
\hline Piteå & Sweden & 1.53 & 0.21 & 336 & 21 \\
\hline Skellefteå & Sweden & 1.83 & 0.57 & 371 & 19 \\
\hline \multicolumn{2}{|c|}{ Bothnian Bay SUM } & 32.0 & 3.4 & 4,900 & 546 \\
\hline \multicolumn{2}{|c|}{ Baltic Sea SUM } & 798 & 296 & 379,000 & \\
\hline \multicolumn{2}{|c|}{ Bothnian Bay/Baltic Sea } & $4.0 \%$ & $1.1 \%$ & $1.3 \%$ & \\
\hline
\end{tabular}

*Estimate (no detailed data available).

\subsection{Oil Spill Accident Statistics}

An oil spill can originate from a ship that is leaking oil due to grounding, collision with another ship or other objects, hull failure, technical failure, fire, explosions or some other reasons. In addition, the spill could originate from a leak in a coastal oil depot.

The most severe oil spill accidents are related to tankers that could carry crude oil volumes up to $500,000 \mathrm{t}$. One of the most recent major accident occurred to Prestige off the coast of Spain and Portugal in 2002 resulting in a 63,000 t spill of heavy oil. Large recovery operations were initiated and reportedly $50,000 \mathrm{t}$ of oil-water mixture was removed at the open sea. Nevertheless, roughly $1,900 \mathrm{~km}$ of coastline was contaminated, and massive clean-up operations were necessary [10].

Despite the steady global increase in the maritime oil transport since $1980 \mathrm{~s}$, the number of oil spills has decreased due to improved marine safety and the adoption of two-hull tankers. The number of spills 


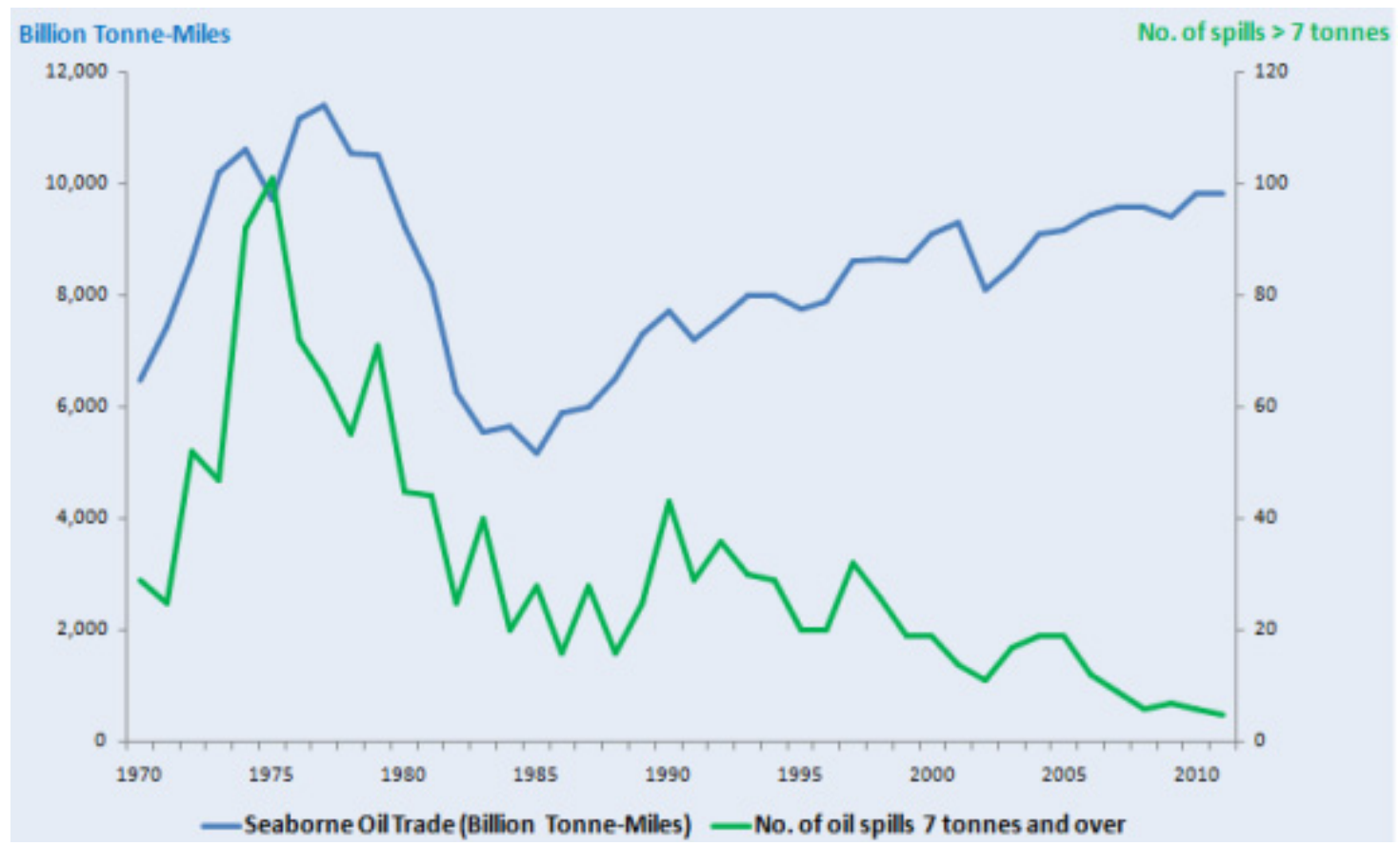

Fig. 2 The seaborne oil trade and number of oil spills since 1969 [10].

Table 2 Registered oil spill accidents ( $\geq 100$ tonnes) in the Baltic Sea from 1969 to 2011 [11].

\begin{tabular}{lclc}
\hline Year, ship name, location & Spill size (tones) & Year, ship name, location & Spill size (tonnes) \\
\hline 1969, Raphael, Finland (Emäsalo) & 250 & 1990, Volgoneft, Sweden (Karlskrona) & 1,000 \\
1969, Palva, Finland (Utö) & 200 & 1992, Unknown, Sweden (Västra Götaland and Halland) & 200 \\
1970, Esso Nordica, Finland (Pellinki) & 600 & 1993, Kihnu, Estonia (Kopli Peninsula) & 100 \\
1970, Pensa, Finland (Hailuoto) & 500 & 1995, Hual Trooper, Sweden (Öresund) & 180 \\
1977, Tsesis, Sweden (Stockholm) & 1,000 & 1998, Weston, Sweden (Västra Götaland) & 4,000 \\
1979, Antonio Gramsci, Finland (Åland) & 5,500 & 1998, Pallas, Germany (Wadden Sea) & 244 \\
1979, Lloyd Bage, Finland (Harmaja) & 100 & 1998, Nunki, Denmark (Kalundborg fjord) & 100 \\
1981, Globe Asimi, Lithuania (Klaipeda) & 16,000 & 2000, Alambra, Estonia (Muuga) & 250 \\
1984, Eira, Finland (Merenkurkku) & 300 & 2001, North Pacific, Lithuania (Klaipeda) & 3,427 \\
1985, Sotka, Finland (Märket) & 370 & 2001, Baltic Carrier, Denmark (Kadetrenden) & 2,700 \\
1987, Antonio Gramsci, Finland (Vaarlahti) & 650 & 2003, Fu Shan Hai, Sweden (Ystad) & 1,200 \\
1987, Tolmiros, Sweden (Västra Götaland) & 400 & 2004, Herakles, Sweden (Grundkallen) & 200 \\
1987, Thuntank 5, Sweden (Bay of Gävle) & 230 & 2006, Runner 4, (Gulf of Finland) & 100 \\
1988, Unknown, Sweden (Torekov) & 287 & & \\
\hline
\end{tabular}

larger than $7 \mathrm{t}$ compared to the seaborne oil trade development since 1969 is illustrated in Fig. 2. Similar trend can be seen in the Baltic Sea statistics. The total cargo volumes in the Finnish ports have increased from roughly 20 million tonnes in 1970 to more than 100 million tonnes in 2012. Also the oil transport volumes in the Baltic Sea have increased rapidly from roughly 120 million tonnes in 2000 to 290 million tonnes in 2010. All registered oil spills larger than $100 \mathrm{t}$ in the
Baltic Sea area between 1969 and 2011 are listed in Table 2. Despite the increase in maritime traffic volumes, the number of accidents has remained roughly the same during different decades $[5,8,10,11]$.

Let us calculate the Baltic sea oil spill accident frequencies by using the compromise version of the PREB estimation method described in Ref. [1]. There are in total 27 oil spill accidents with spill size at least 100 tonnes, and the corresponding accident frequency 
is $0.64 / \mathrm{y}$. The frequency for an accident with a spill size ranging from 100 to 1000 tonnes is $0.50 / y$ ( 21 accidents), and the frequency for a large spill over 1000 tonnes is $0.15 / \mathrm{y}$ ( 6 accidents).

\section{Oil Spill Behavior}

\subsection{The Weathering Process}

Quite sophisticated models (e.g., Spillmod by Russian Sergey Ovsienko, State Oceanographic Institute, Russia), have been developed to evaluate oil spill behaviour after an oil spill accident. Spill movement and volume development is affected by several factors, such as accident location, oil properties, local hydrometeorological conditions (mostly wind and currents) and volume and intensity of the leakage. After oil is released in the sea, a process called "weathering" (Fig. 3) begins, including rapid loss of volatile materials and mixing with water due to wind and waves. The oil becomes denser, more viscous and often forms emulsions [12, 13].

\subsection{Crude Oil and Oil Products}

Crude oil (also called petroleum) is a naturally occurring liquid found in geologic formations beneath the Earth's surface. The densities of crude oils vary from $0.7 \mathrm{~kg} / \mathrm{dm}^{3}$ to $1.0 \mathrm{~kg} / \mathrm{dm}^{3}$ (typically around 0.85 $\mathrm{kg} / \mathrm{dm}^{3}$ ) and also the viscosity, color and other properties are different depending on the crude oil product in question.

Crude oils are mixtures of different hydrocarbons with different chemical properties. The different components can be separated by fractional distillation that allows the separation of chemical components with different boiling points one by one. The lightest distillates, such as liquified petroleum gas, propane and butane, have boiling temperatures below zero degrees $\left({ }^{\circ} \mathrm{C}\right)$ and are thus gases in room temperature. Some of the most important medium and heavy distillates are listed in Table 3. The terminology used is not completely established and products are called with different names in different countries. Some of the products listed (e.g., petrol) are not pure distillation products because they are enhanced with different additives. The products with a higher density are generally more viscose, less volatile and have higher boiling points. Residual fuel oil is actually not a distillate but a more impure residual product that is left when lighter components have been distilled away. Other significant raw oil distillate products not included in the table include: alkanes, lubricants, tar, asphalt, petroleum coke and aromatic petrochemicals.

\subsection{Oil Spill Volume Development}

Oil dissipation and persistence depend on its properties. Light crude oil distillates, such as petrol,

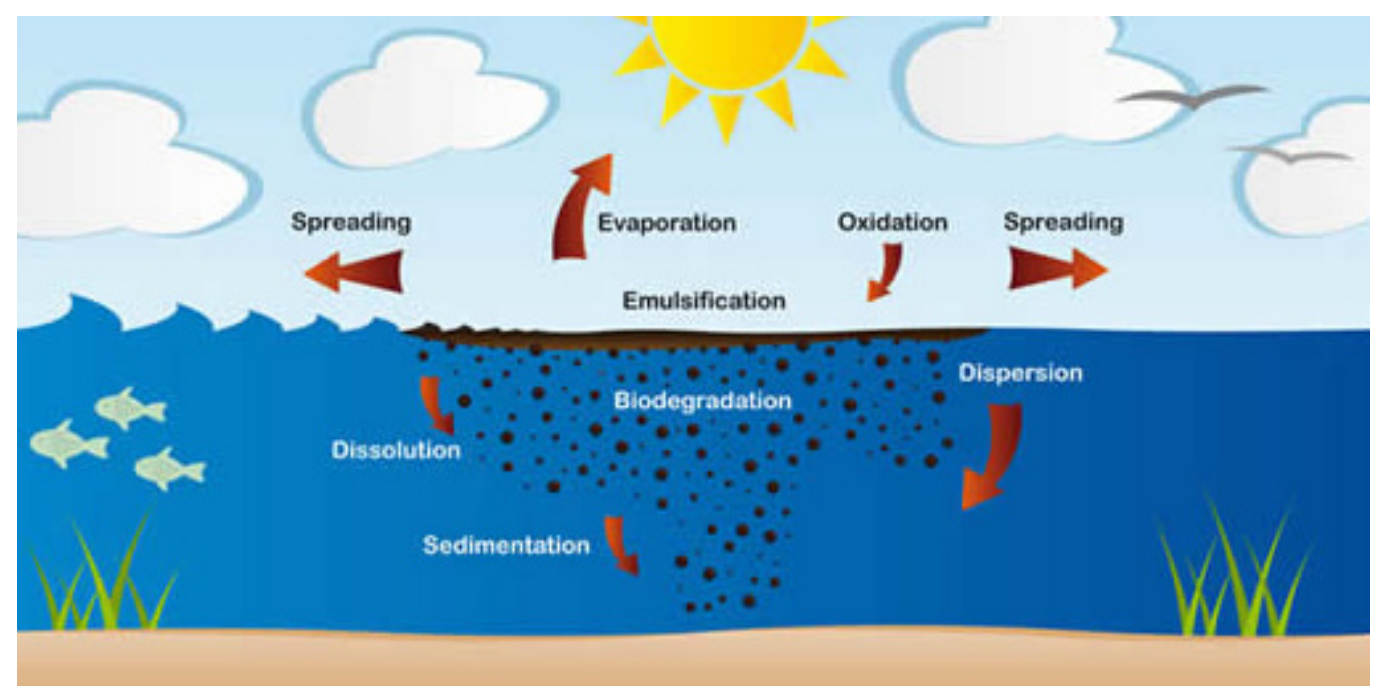

Fig. 3 Oil spill weathering process [13]. 
Table 3 Some important oil products.

\begin{tabular}{|c|c|c|}
\hline Fuel product & Density $\left(\mathrm{kg} / \mathrm{dm}^{3}\right)$ & Primary use \\
\hline Petrol (gasoline) & $0.71-0.77$ & Vehicle internal combustion engines \\
\hline Kerosene, jet fuel (paraffin) & $0.78-0.81$ & Aircraft jet and gas turbine engines, cooking, lighting \\
\hline Diesel fuel & $\approx 0.83$ & Diesel engines in cars, buses, trucks and ships, electricity production \\
\hline Light fuel oil & $0.80-0.90$ & Heating, diesel engines \\
\hline Crude oil (petroleum) & $\approx 0.85(0.70-1.00)$ & Raw product of different oil products \\
\hline $\begin{array}{l}\text { Distillate fuel oil (heavy fuel oil, } \\
\text { marine gas oil) }\end{array}$ & $0.89-0.92$ & Ships, other large diesel engines \\
\hline $\begin{array}{l}\text { Residual fuel oil (heavy fuel oil, } \\
\text { marine fuel oil, bunker fuel) }\end{array}$ & $0.96-1.01$ & Ships, heating plants \\
\hline
\end{tabular}

kerosene and diesel oil evaporate quickly and do not require any cleaning-up measures. Lighter products also have a smaller effect on the intake screens and heat exchangers of the power plant. Heavier products, such as crude oils, fuel oils and lubricating oils, are much more persistent.

The development of the oil-water mixture volume as a function of time has been assessed by categorizing the oil products into four different categories according to their density. The volume development and the categorization of oil products according to Ref. [13] are presented in Fig. 4. At an early phase of the accident, the volume of oil waste increases in groups II, III and IV because of the viscous emulsions formed with water.

\subsection{Oil Spill Movement}

Spreading of oil is mainly affected by oil viscosity and also by environmental conditions. If a 10,000 $\mathrm{t}$ oil spill occurs, the estimated spill area after one day is roughly $10 \mathrm{~km}^{2}$ and the oil layer thickness roughly 1 $\mathrm{mm}$. After three days, the estimated area is $15-20 \mathrm{~km}^{2}$ and thickness $0.5 \mathrm{~mm}$ and after five days, $20-30 \mathrm{~km}^{2}$ and $0.3 \mathrm{~mm}$. If the oil accident occurs during winter time, ice partially prevents the spill from spreading. Part of the oil could, however, spread under the ice sheet. Also oil combating is more difficult during winter. It has been estimated that if more than $10,000 \mathrm{t}$ of oil come ashore, more than $100 \mathrm{~km}$ of coast is contaminated. Respectively, $10-100 \mathrm{~km}$ of shore is assumed to be affected if the amount of oil is $1,000-10,000 \mathrm{t}$. If the oil amount is less than $1,000 \mathrm{t}$, less than $10 \mathrm{~km}$ of shoreline is affected [4].

The oil spill is moved by wind and water currents. There are no strong and stable currents in the Bothnian Bay, and thus the water movements are fluctuating and unpredictable. The wind only affects the water movement in the summer. When the sea is covered by an ice sheet (on average from November to May), the water movement is mostly affected by river flow rates, water level fluctuations and temperature and salinity differences [14].

The average wind speed in the Bothnian Bay is roughly $7 \mathrm{~m} / \mathrm{s}$ and the probabilities of different wind directions are presented in Fig. 5 (left picture). Roughly half of the time, the wind direction is between south and west [15].

In the Gulf of Bothnia, two main currents can be recognized: one in the Bothnian Bay and another one in the Bothnian Sea (Fig. 5, right picture). The Coriolis effect causes the water to flow anticlockwise and thus the water flows northwards in the Finnish coast and southwards in the Swedish coast. The quark is an intermediate zone between these two main currents. The average current speeds in the Baltic Sea are typically $5-10 \mathrm{~cm} / \mathrm{s}$. The measurements performed around Hanhikivi confirm that the prevailing current direction is from southwest to northeast and the average current speed near the surface is less than 10 $\mathrm{cm} / \mathrm{s}$, whereas the highest speed measured is $50 \mathrm{~cm} / \mathrm{s}$ [14].

It has been roughly estimated that the oil spill travel speed is $100 \%$ of the water current speed and $3 \%$ of the wind speed [12]. By using the estimates presented 


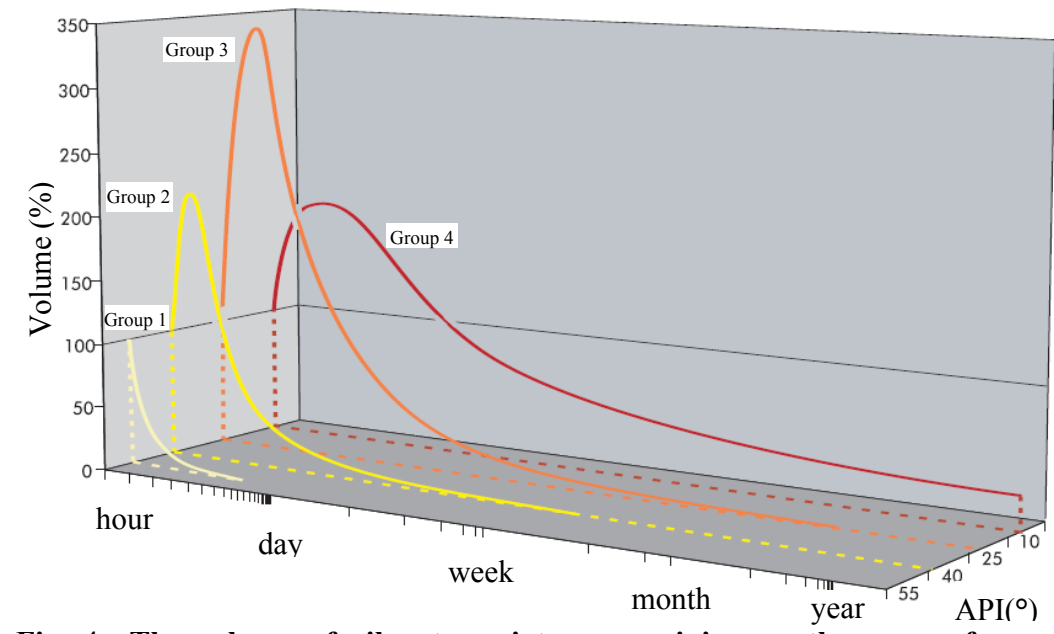

\begin{tabular}{|l|l|l|}
\hline & $\begin{array}{l}\text { Density } \\
\left(\mathrm{kg} / \mathrm{dm}^{3}\right)\end{array}$ & Examples \\
\hline I & $<0.80$ & Petrol, kerosene \\
\hline II & $0.80-0.85$ & $\begin{array}{l}\text { Diesel fuel, light fuel oil, } \\
\text { Abu Dhabi crude oil }\end{array}$ \\
\hline III & $0.85-0.95$ & $\begin{array}{l}\text { Distillate fuel oil, Arabian } \\
\text { light crude oil, North Sea } \\
\text { crude oil }\end{array}$ \\
\hline IV & $>0.95$ & $\begin{array}{l}\text { Residual fuel oil, } \\
\text { Venezuelan crude oil }\end{array}$ \\
\hline
\end{tabular}

Fig. 4 The volume of oil-water mixture remaining on the sea surface as a function of time for different oil product categories [13].
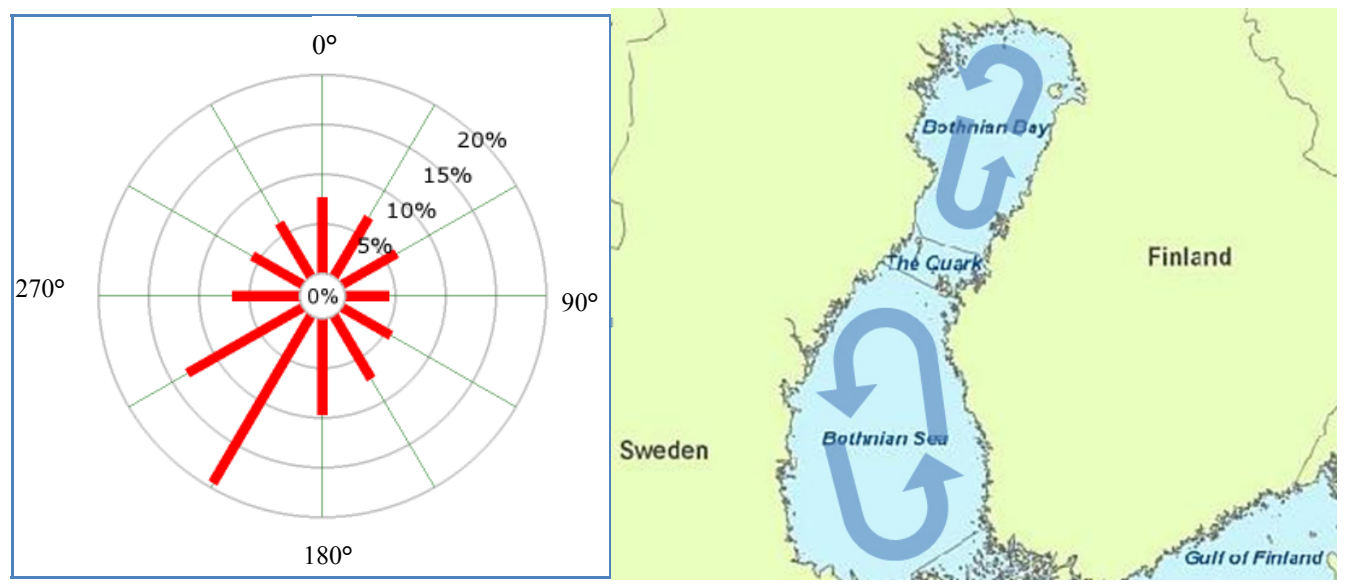

Fig. 5 The average wind directions in the Bothnian Bay (40 $\mathrm{km}$ off Hanhikivi) [15] and the main currents in the Gulf of Bothnia [14].

(typical sea current speed $5-10 \mathrm{~cm} / \mathrm{s}$ to northeast and typical wind speed $7 \mathrm{~m} / \mathrm{s}$ wind to northeast), we can assess that the typical oil spill drifting speed and direction in the Bothnian Bay is approximately $30 \mathrm{~cm} / \mathrm{s}$ to northeast. This equals $1.1 \mathrm{~km} / \mathrm{h}$ or $26 \mathrm{~km} / \mathrm{d}$.

\section{Oil Combat}

\subsection{Oil Combat Techniques}

Several maritime oil combat measures are available and have been discussed in Ref. [12]. When assessing the oil spill risk for Hanhikivi 1, it is important to evaluate the open sea combat measures that can be used to prevent the oil spill from reaching the plant sea water intake.
Oil booms are used to surround and concentrate an oil spill in the open sea to enable oil recovery. Booms are also effective in protecting small and important targets in the coast, such as power plants. Booms are typically deployed by using boats, but deployment from shore or helicopter is also possible. The effectiveness of booming depends on the oil properties and weather conditions. If the spill is already spread out on a large area, it might be impossible to surround it. Heavy oils may go under the booms, and strong wind and high waves could cause the oil to splash over the boom. The booms could also be carried away or be completely broken up by wind, wave and currents. Fig. 6 illustrates a deployed oil boom in the Kalajoki harbour. This is a typical boom used in Finland with an 


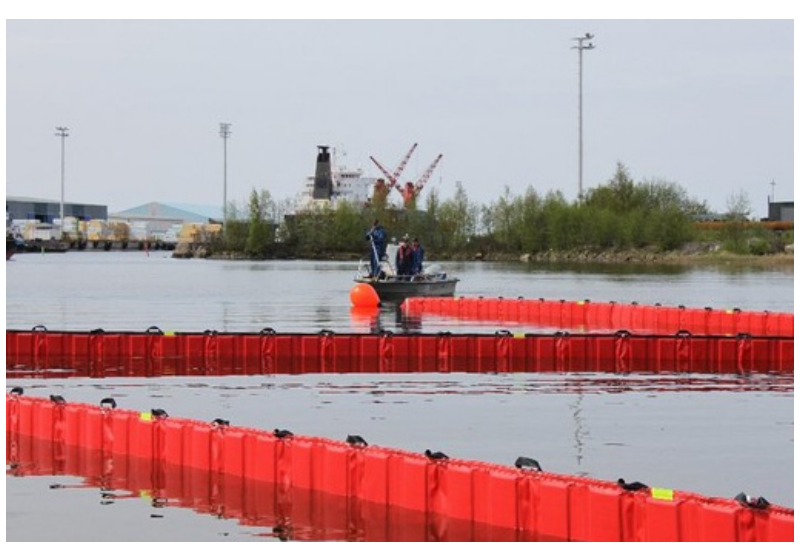

Fig. 6 A deployed oil boom in the Kalajoki harbor [16].

approximate one-meter height (1/3 of which above surface) and consisting of consecutive sections chained together. There are also single-use booms that can be used to absorb oil.

Specialized ships equipped with skimmers are used for collecting oil from the sea surface. Different types of skimmers (mechanical, weir, oleophilic, vacuum) can be used for collecting oil products with different characteristics. Oil collection is usually only effective immediately after the spill because the weathering process causes oil to spread, fragment and disperse under the influence of wind, waves and currents. It has been estimated that the effective gathering time after the spill is three days in the case of crude oil and 10 days in the case of heavier and more persistent fuel oil. In the winter, the ice sheet prevents oil spreading and the effective gathering times could be even three times longer [4].

Other possible measures that can be used for oil combating are for example bubble barriers, burning of oil and dispersants. These are discussed in more detail in Ref. [13].

\subsection{Preparedness in the Bothnian Bay}

The Finnish Environment Institute (Suomen ympäristökeskus, SYKE) has set the following targets for oil combat measures in the Gulf of Bothnia [4, 17]:

- Capacity to gather 5,000 t of oil at the open sea (during three days in summertime and during 10 days in wintertime);
- Capacity to deploy coastal oil boom: $2 \mathrm{~km}$ within $12 \mathrm{~h}$ of the accident, $12 \mathrm{~km}$ within $24 \mathrm{~h}, 42 \mathrm{~km}$ within $48 \mathrm{~h}, 80-90 \mathrm{~km}$ within $72 \mathrm{~h}$.

SYKE maintains 13 oil combating stations equipped with oil combating boats and ships, oil booms and other material. Two of the stations are located in the Bothnian Bay (Oulu and Rahja). There are 16 oil combat ships that are ready to depart for an oil combat mission after a delay of 0-48 $\mathrm{h}$ The ships are equipped with extendable oil gathering arms that allow sweeping widths from $19 \mathrm{~m}$ to $42 \mathrm{~m}$ and oil gathering capacities ranging from $35 \mathrm{~m}^{3} / \mathrm{h}$ to $78 \mathrm{~m}^{3} / \mathrm{h}$. In addition to oil combat ships, there are roughly 100 smaller oil combat boats that can be used for oil booming and other support operations [18].

If an oil spill occurs, the ship captain is obliged to immediately report the accident to the Maritime Rescue Coordination Centre. In the case of an oil spill, the Finnish oil combat boats and ships stationed in the Bothnian Bay coast would arrive to the accident location first. The local vessels would be supported by Finnish oil combat vessels from other areas and by vessels from other Baltic Sea countries, specifically from Sweden. These additional ships would arrive gradually within 1-4 days.

\subsection{Plant Protection against Oil Spills}

Oil booms are the most effective measure in protecting a nuclear power plant against oil spills. Booms can be permanent or they can be placed on demand. In the latter case, there shall be a sufficient preparedness (boats and personnel) for rapid boom deployment. Booms can be placed in the immediate vicinity of the intake and discharge side and further away on the sea. Also the intake structure design has some effect on the oil spill consequences. A deep intake collects less oil than a surface intake. It shall also be possible to clean the fine screens and basket filters effectively if they are contaminated by oil. Furthermore, the plant personnel shall be informed without delay from any nearby spills and there shall be operating 
procedures to guide the actions of the plant personnel.

The risk related to oil spills is decreased if it is possible to take cooling water via an auxiliary intake or from the discharge side. The oil risk is also decreased by enabling sufficient measures for cooling also in the case of loss of primary ultimate heat sink (i.e., the sea). The Finnish regulatory guides on nuclear safety YVL (ydinvoimalaitos) guides require that it shall be possible to remove residual heat also by using an alternative, independent heat sink.

\section{Results}

The frequency of the oil initiating event (significant amount of oil enters the intake tunnel) in the Hanhikivi plant is estimated by considering two different accident scenarios: a medium spill (100-1,000 t, mean size roughly $550 \mathrm{t})$ and a large spill $(>1,000 \mathrm{t}$, mean size roughly $4,000 \mathrm{t}$ ). The risk related to spills smaller than $100 \mathrm{t}$ is assumed insignificant. A medium spill is possible if any type of ship carrying sufficient amount of fuel oil suffers an accident. For example, the fuel capacity of a large passenger cruise ship exceeds 1,000 t. Ships need fuel to produce the propulsion force, but also for producing all the electricity needed in the ship. A large spill can be caused by an accident of a tanker carrying various oil products that form a floating spill on the sea surface.

\subsection{Spill Frequencies}

Ship fuel oils and light and heavy fuel oils transported in tankers in the Bothnian Bay are relatively heavy and persistent oil products belonging mainly to groups 3 and 4 in the categorization of Fig. 4 . Due to the high persistence of these oil products, the whole Bothian Bay is considered as a potential accident area. However, because of the prevailing currents (see Fig. 5), accidents occurring further away in the Baltic Sea are not considered a threat to the Hanhikivi plant.

The frequency for an oil spill accident with a volume ranging from $100 \mathrm{t}$ to $1,000 \mathrm{t}$ is received by assuming 21 events in the Baltic Sea during 43 years (see Table
2 ), and assuming that $2 \%$ of the Baltic Sea accidents occur in the Bothnian Bay (see Table 1): $(21.5 / 43 \mathrm{y}) \times$ $0.02=1.0 \times 10^{-2} / \mathrm{y}$. Similarly, the large spill $(>1,000 \mathrm{t}$, 6 events) frequency estimate is: $(6.5 / 43 \mathrm{y}) \times 0.02=3.0$ $\times 10^{-3} / \mathrm{y}$.

\subsection{Impact Probability}

If an oil accident occurs in the Bothnian Bay, the spill should travel to Hanhikivi to have any effect on the plant operation. According to Section 4.4, we assume that a medium spill contaminates $10 \mathrm{~km}$ of coastline and a large spill $40 \mathrm{~km}$. The Bothnian Bay coastline length is roughly $700 \mathrm{~km}$ and the Finnish coastline length in the Bothnian Bay is $350 \mathrm{~km}$. Based on the wind rose presented in Fig. 5, we estimate that the wind blows between southwest and north with a $60 \%$ probability causing the spill to land on the Finnish coast. By using the assumptions presented, we can calculate that the medium spill impact probabilities on Hanhikivi is: $0.60 \times 10 \mathrm{~km} / 350 \mathrm{~km} \approx 0.017$. Similarly, the large spill impact probability is: $0.60 \times 40 \mathrm{~km} / 350$ $\mathrm{km} \approx 0.069$.

\subsection{Spill Warning}

In the case of a significant oil spill, the ship captain is obliged to report to the Finnish Maritime Rescue Coordination Centre. The warning could fail if the ship captain would, for some reasons, intentionally decide not to report the event. Also the communication equipment in the ship could fail, although there are probably alternative methods for communication. In the most drastic scenario, the ship could sink so quickly that there would be no time to report the event. Even if the ship itself could not give the warning, other bypassing ships or airplanes could do that. There is no data available to assess how often large oil spills are left unreported. According to the information presented above, it can be assumed that a duly warning is received with a high probability. By using expert judgement, we assume that no early warning is obtained with a probability of $1 \%$. 


\subsection{Open Sea Oil Combat}

The most effective oil collection time is immediately after the spill because the spill spreads out quickly. Thus, we assume that the open sea oil combat fails if no early oil spill warning is received.

SYKE is prepared to collect 5,000 t of oil in the Gulf of Bothnia area during three days. Thus we can assume that the open sea oil combat succeeds with a high probability if an early warning is received and if the weather and sea conditions are not very harsh. Strong wind, high waves and strong currents cause the oil to spread out quickly, which makes the oil booming and collection very difficult.

We assume that a medium oil spill combat fails if the wind speed exceeds $14 \mathrm{~m} / \mathrm{s}$ (corresponding average wave height is roughly $3 \mathrm{~m}$ ). According to measurement data, these conditions prevail in the Bothnian Bay area with a probability of 0.09 [19]. Similarly, we assume the large oil spill combat to fail if the wind speeds exceeds $10 \mathrm{~m} / \mathrm{s}$ (wave height $1.5 \mathrm{~m}$ ), the probability of which is 0.35 [19].

\subsection{Near Hanhikivi Oil Combat}

If strong wind causes the failure of open sea oil combat, there is also a relatively high probability that also the oil booms near Hanhikivi fail. However, the success probability of oil combat is somewhat larger near Hanhikivi than in the open sea. The open sea oil combat aims at both booming and collecting the spilled oil, whereas near Hanhikivi, the only aim is to prevent the oil spill from drifting to the intake. It could also occur that the strong wind settles before the spill reaches Hanhikivi several days after the accident. By taking these factors into account, we use expert judgement and estimate the following failure probabilities for near Hanhikivi oil combat if the open sea oil combat has failed due to strong wind: medium spill (33\%) and large spill (50\%).

If the open sea oil combat failed because no early warning was received, the spill might be detected so late that it reaches the Hanhikivi intake harbour before the oil boom is placed. If the boom is placed on time, the oil combat success probability can be estimated to be relatively high. We assume the same failure probabilities for near Hanhikivi oil combat also in this case (medium 33\%, large 50\%).

\subsection{Event Trees}

The event trees for medium and large spills are presented in Figs. 7 and 8. The estimated medium spill frequency is $1.0 \times 10^{-2} / \mathrm{y}$, and the spill reaches the plant

\begin{tabular}{|c|c|c|c|c|c|c|}
\hline $\begin{array}{l}\text { Medium spill frequency } \\
\text { in Bothnian Bay }\end{array}$ & $\begin{array}{l}\text { Spill drifts away } \\
\text { from Hanhikivi }\end{array}$ & $\begin{array}{l}\text { Early warning } \\
\text { received }\end{array}$ & $\begin{array}{l}\text { Open sea oil } \\
\text { combat successful }\end{array}$ & $\begin{array}{l}\text { Hanhikivi oil } \\
\text { combat successful }\end{array}$ & Consequence & $f(1 / y)$ \\
\hline \multirow[t]{11}{*}{$1.0 \mathrm{E}-02$} & $9.8 \mathrm{E}-01$ & & & & Spill drifts away from Hanhikivi & $9.8 \mathrm{E}-03$ \\
\hline & $1.7 \mathrm{E}-02$ & $9.9 \mathrm{E}-01$ & $9.1 \mathrm{E}-01$ & & Spill stopped at open sea & $1.5 \mathrm{E}-04$ \\
\hline & & & $9.0 \mathrm{E}-02$ & $6.7 \mathrm{E}-01$ & Spill stopped near Hanhikivi & $1.0 \mathrm{E}-05$ \\
\hline & & & & $3.3 \mathrm{E}-01$ & Spill enters the intake & $5.0 \mathrm{E}-06$ \\
\hline & & $1.0 \mathrm{E}-02$ & & $6.7 \mathrm{E}-01$ & Spill stopped near Hanhikivi & $1.1 \mathrm{E}-06$ \\
\hline & & & & $3.3 \mathrm{E}-01$ & Spill enters the intake & $5.6 \mathrm{E}-07$ \\
\hline & & & & & SUMMARY & \\
\hline & & & & & Spill drifts away from Hanhikivi & $9.8 \mathrm{E}-03$ \\
\hline & & & & & Spill stopped at open sea & $1.5 \mathrm{E}-04$ \\
\hline & & & & & Spill stopped near Hanhikivi & $1.1 \mathrm{E}-05$ \\
\hline & & & & & Spill enters the intake & $5.6 \mathrm{E}-06$ \\
\hline
\end{tabular}

Fig. 7 Event tree for a medium oil spill (100-1,000 t). 


\begin{tabular}{|c|c|c|c|c|c|c|}
\hline $\begin{array}{l}\text { Large spill frequency in } \\
\text { Bothnian Bay }\end{array}$ & $\begin{array}{l}\text { Spill drifts away } \\
\text { from Hanhikivi }\end{array}$ & $\begin{array}{l}\text { Early warning } \\
\text { received }\end{array}$ & $\begin{array}{l}\text { Open sea oil } \\
\text { combat successful }\end{array}$ & $\begin{array}{l}\text { Hanhikivi oil } \\
\text { combat successful }\end{array}$ & Consequence & $f(1 / y)$ \\
\hline \multirow[t]{11}{*}{$3.0 \mathrm{E}-03$} & 9.3E-01 & & & & Spill drifts away from Hanhikivi & $2.8 \mathrm{E}-03$ \\
\hline & $6.9 \mathrm{E}-02$ & $9.9 \mathrm{E}-01$ & $6.5 \mathrm{E}-01$ & & Spill stopped at open sea & $1.3 \mathrm{E}-04$ \\
\hline & & & $3.5 \mathrm{E}-01$ & $5.0 \mathrm{E}-01$ & Spill stopped near Hanhikivi & 3.6E-05 \\
\hline & & & & $5.0 \mathrm{E}-01$ & Spill enters the intake & 3.6E-05 \\
\hline & & $1 . \mathrm{OE}-02$ & & 5.0E-01 & Spill stopped near Hanhikivi & $1.0 \mathrm{E}-06$ \\
\hline & & & & $5.0 \mathrm{E}-01$ & Spill enters the intake & $1.0 \mathrm{E}-06$ \\
\hline & & & & & SUMMARY & \\
\hline & & & & & Spill drifts away from Hanhikivi & $2.8 \mathrm{E}-03$ \\
\hline & & & & & Spill stopped at open sea & $1.3 \mathrm{E}-04$ \\
\hline & & & & & Spill stopped near Hanhikivi & 3.7E-05 \\
\hline & & & & & Spill enters the intake & 3.7E-05 \\
\hline
\end{tabular}

Fig. 8 Event tree for a large oil spill $(>1,000 \mathrm{t})$.

Table 4 Sensitivity analysis for the oil initiating event frequency by using both conservative and optimistic assumptions for different parameters.

\begin{tabular}{lllllllll}
\hline & \multicolumn{3}{c}{ Medium spill parameters } & \multicolumn{3}{c}{ Large spill parameters } & \multicolumn{2}{c}{$f_{\text {CONS }}$} \\
\cline { 2 - 9 } & BE & Cons. & Opt. & BE & Cons. & Opt. & $(1 / \mathrm{y})$ & $(1 / \mathrm{y})$ \\
\hline Spill frequency & $1.0 \mathrm{E}-02$ & $5.3 \mathrm{E}-02$ & $2.5 \mathrm{E}-03$ & $3.0 \mathrm{E}-03$ & $1.6 \mathrm{E}-02$ & $7.6 \mathrm{E}-04$ & $2.3 \mathrm{E}-04$ & $1.1 \mathrm{E}-05$ \\
Spill drifts to Hanhikivi & $1.7 \mathrm{E}-02$ & $5.1 \mathrm{E}-02$ & $7.1 \mathrm{E}-03$ & $6.9 \mathrm{E}-02$ & $2.6 \mathrm{E}-01$ & $1.4 \mathrm{E}-02$ & $1.6 \mathrm{E}-04$ & $9.8 \mathrm{E}-06$ \\
No early warning & $1.0 \mathrm{E}-02$ & $1.0 \mathrm{E}-01$ & $1.0 \mathrm{E}-03$ & $1.0 \mathrm{E}-02$ & $1.0 \mathrm{E}-01$ & $1.0 \mathrm{E}-03$ & $5.3 \mathrm{E}-05$ & $4.1 \mathrm{E}-05$ \\
Open sea oil combat fails & $9.0 \mathrm{E}-02$ & $3.3 \mathrm{E}-01$ & $2.0 \mathrm{E}-02$ & $3.5 \mathrm{E}-01$ & $6.7 \mathrm{E}-01$ & $1.0 \mathrm{E}-01$ & $8.9 \mathrm{E}-05$ & $1.3 \mathrm{E}-05$ \\
Hanhikivi oil combat fails & $3.3 \mathrm{E}-01$ & $6.6 \mathrm{E}-01$ & $1.0 \mathrm{E}-01$ & $5.0 \mathrm{E}-01$ & $8.0 \mathrm{E}-01$ & $2.0 \mathrm{E}-01$ & $7.0 \mathrm{E}-05$ & $1.6 \mathrm{E}-05$ \\
\hline
\end{tabular}

intake with a $0.06 \%$ probability (frequency is $5.6 \times$ $\left.10^{-6} / \mathrm{y}\right)$. The estimated large spill frequency is $3 \times 10^{-3} / \mathrm{y}$, and the spill reaches the plant intake with a $1.2 \%$ probability (frequency is $3.7 \times 10^{-5} / \mathrm{y}$ ).

The oil initiating event for the PRA (probabilistic risk assessment) of Hanhikivi plant was defined to be an event where significant amount of oil enters the intake tunnel. The frequency for this initiating event is obtained by summing up the two scenarios:

$$
5.6 \times 10^{-6} / \mathrm{y}+3.7 \times 10^{-5} / \mathrm{y}=4.2 \times 10^{-5} / \mathrm{y}
$$

\subsection{Sensitivity and Uncertainty Analysis}

The event tree probabilities include somewhat large uncertainties. Thus, sensitivity analysis was performed by recalculating the results using both conservative and optimistic estimates for each parameter. The parameter values and the effect on the results are presented in Table 4.
The results indicate that the largest uncertainties are related to accident frequency estimates and spill drifting direction. The uncertainties in the results could be decreased by analysing the following factors in more detail: accidents smaller than $100 \mathrm{t}$, accidents occurring elsewhere than in the Bothnian Bay, coastal oil depot leaks, the trends in maritime traffic volumes and accident probabilities, the oil spill behaviour after the leak, the types and characteristics of oil products transported in the Bothnian Bay, oil spill behaviour and oil combat in the wintertime and oil effects on a nuclear power plant.

\section{Conclusion}

In this report, the risk of a maritime oil spill accident near the Hanhikivi nuclear power plant was evaluated. If the floating oil spill drifts to Hanhikivi and oil combat measures fail, oil could enter the sea water 
intake, block the fine screens and basket chain filters and lead to loss of sea water cooling.

By considering the maritime traffic, oil transport and oil spill accident data in the Baltic Sea area, it was evaluated that a nearby oil spill of medium size (100-1,000 t) occurs with a frequency of $1.0 \times 10^{-2} / y$ and an oil spill of larger size $(>1,000 \mathrm{t})$ with a frequency of $3.0 \times 10^{-3} / \mathrm{y}$. The probability of a major oil spill accident is relatively low in the Bothnian Bay due to the small oil product transportation volumes and the lack of crude oil transports.

The probability that the spill drifts to Hanhikivi and oil combat measures fail was assessed by using event tree analysis. The typical wind and current conditions in the Bothnian Bay cause the spill to float towards northeast with an approximate speed of $30 \mathrm{~cm} / \mathrm{s}$, which equals $1.1 \mathrm{~km} / \mathrm{h}$ or $26 \mathrm{~km} / \mathrm{d}$. Light oil products, such as petrol, evaporate quickly, but heavy and persistent ship fuel oils could travel over long distances. Open sea oil combat measures are coordinated by the Finnish Environment Institute and include booming of the spill and gathering oil with specialized ships. There is a capacity to gather $5,000 \mathrm{t}$ of oil in the open sea during three days, provided that the wind and sea conditions are not specifically harsh. Also the Hanhikivi plant can be protected by using deployable oil booms. According to the results of the event tree analysis, significant amount of oil could enter the Hanhikivi plant intake tunnel with a frequency of $4.2 \times 10^{-5} / \mathrm{y}$.

The most significant uncertainties are related to the accident frequency estimation and oil spill drifting direction. The uncertainties could be decreased by performing more detailed analysis. However, due to the low risk of the event, further analysis is not considered necessary.

\section{References}

[1] Vaurio, J., and Jänkälä, K. 2006. "Evaluation and Comparison of Estimation Methods for Failure Rates and Probabilities.” Reliability Engineering and System Safety 91: 209-21.

[2] Bergroth, N., Jänkälä, K., and Ovsienko. S. 2006. “Oil
Spill Risk Assessment for Loviisa Nuclear Power Plant.” Presented at the 8th International Conference on Probabilistic, New Orleans, Louisiana, USA.

[3] Tunturivuori, L. 2013. "External Hazards in the PRA of Olkiluoto 1 and 2 NPP Units-Accidental Oil Spills." Presented at the OECD NEA Workshop on PSA of Natural External Hazards Including Earthquakes, Prague.

[4] Ministry of the Environment. 2011. Activities in Major Oil Spill Accidents. Arranging Oil Combat, Management and Communication. A report from the Ministry of the Environment 26/2011.

[5] Stankiewicz, M., Backer, H., and Vlasov, N. 2010. "Maritime Activities in the Baltic Sea-An Integrated Thematic Assessment on Maritime Activities and Response to Pollution at Sea in the Baltic Sea Region." In Proceedings of Baltic Sea Environment, 123.

[6] European Commission. 2006. "Eurostat, European transport statistics database." European Commission Accessed August 10, 2013. http://epp.eurostat.ec.europa. $\mathrm{eu} /$ portal/page/portal/transport/data/database.

[7] Saurama, A., Holma, E., and Tammi, K. 2008. Baltic Port List 2006. Annual Cargo Statistics of Ports in the Baltic Sea Region. A publication from the Centre for Maritime Studies, University of Turku.

[8] Finnish Port Association. 2013. "Statistics produced by Finnish Port Association." Finnish Port Association. Accessed July 8, 2013. http://www.finnports. com/eng/statistics.

[9] Transport Group. 2006. "Sveriges Hamnar Statistik Swedish Port Statistics." Transport Group. Accessed July 16, 2013. http://www.transportgruppen.se/Forbund Container/Svenska-hamnar/Branschfragor/Hamnstatistik/.

[10] International Tanker Owners Pollution Federation. 2013. Oil tanker spill statistics 2012. Technical report.

[11] Pålsson, J. 2012. Oil Spill Preparedness in the Baltic Sea Countries. Report written for the Baltic Master II project, World Maritime University.

[12] International Tanker Owners Pollution Federation. 1987. Effects of Oil Pollution on Major Municipal and Industrial Sea Water Abstractions. Final report to the Commission of the European Communities Directorate-General for the Environment, Consumer Protection and Nuclear Safety.

[13] International Tanker Owners Pollution Federation. 2013. Handbook 2013/14. Handbook.

[14] The Finnish Meteorological Institute. 2013. "Wind Statistics." The Finnish Meteorological Institution. Accessed September 2, 2013. http://ilmatieteenlaitos. fi/tuulitilastot.

[15] Finnish Wind Atlas. 2013. "Finnish Wind Atlas, Maps of 
Average Wind Speed." Ministry of Employment and Economy, Finnish Meteorological Institute, Motiva Oy. Accessed August 24, 2013. http://www.tuuliatlas.fi.

[16] Siermala, E., and Anttio E. 2013. "Kalajoen Satama Öljyntorjuntaa (Port of Kalajoki - Oil combat)." Port of Kalajoki Press release. Accessed August 22, 2013. http://www.portofkalajoki.com/ oeljyntorjuntaa.html.

[17] Jolma, K.. 2009. A Study on Developing the Oil Combat Preparedness of the State and Municipalities in
2009-2018 Technical report, the Finnish Environment Institute.

[18] Finland's Environmental Administration. 2014. "Environmental Emergency Response in Finland." Accessed February 28, 2014. http://www.environment.fi.

[19] The Finnish Environment Institute. 2013. "The Baltic Sea Portal." The Finnish Environment Institute, the Finnish Meteorological Institute, Ministry of the Environment. Accessed August 13, 2013. http:// www.itameriportaali.fi. 